\title{
Desigualdades sociais e duas formas de particularismo na sociedade brasileira
}

\author{
Social inequalities and two forms \\ of particularism in Brazilian society
}

Jeni Vaitsman 1

\footnotetext{
1 Departamento de Ciências Sociais, Escola Nacional de Saúde Pública, Fundação Oswaldo Cruz. Rua Leopoldo Bulhões 1480, Rio de Janeiro, $R J$ 21041-210, Brasil. vaitsman@ensp.fiocruz.br
}

\begin{abstract}
Based on a discussion by contemporary social theorists concerning Brazil's historical formation and its incorporation into a project for a modern society, the article identifies two forms of particularism - differences and personal relations - which limit access to the market and to rights in the public sphere. The particularism of differences produces social and symbolic exclusion, hindering the formation of feelings of belonging and social interdependence, necessary for effective institutionalization of universalism in the public sphere. The particularism of personal relations permeates new institutional arrangements that incorporate participation by society in public policy management. Still, although these new arrangements and arenas bear the political and cultural marks of Brazil's historical background, they constitute open possibilities for a new equation involving universalism and particularism.
\end{abstract}

Key words Social Inequity; Universalism; Particularism; Interpersonal Relations

Resumo Com base em uma discussão de autores contemporâneos sobre a formação histórica do Brasil e sua incorporação ao projeto de sociedade moderna, o artigo identifica duas formas de particularismo - o das diferenças e o das relações pessoais - que na esfera pública constrangem o acesso ao mercado e aos direitos. O particularismo das diferenças produz exclusão social e simbólica, dificultando a formação dos sentimentos de inclusão e interdependência social, necessários para a efetiva institucionalização do universalismo na esfera pública. O particularismo das relações pessoais atravessa os novos arranjos institucionais que incorporam a participação da sociedade na gestão das políticas públicas. Contudo, ainda que a constituição desses novos arranjos e arenas tragam as marcas políticas e culturais da trajetória histórica brasileira, constituem possibilidades abertas para uma nova equação entre universalismo e particularismo. Palavras-chave Iniqüidade Social; Universalismo; Particularismo; Relações Interpessoais 


\section{Introdução}

Neste artigo, procuro refletir sobre as perguntas que nortearam as discussões da oficina Instituições, Cultura, Política e Desigualdade, no seminário que é objeto deste suplemento de Cadernos de Saúde Pública: (1) Quais as implicações da tradição política e cívica brasileira para a qualidade e a "eficácia" das instituições, bem como para a produção de pobreza e desigualdade? (2) Seria possível incorporar positivamente a tradição brasileira ao processo de formação de novos arranjos institucionais, novos paradigmas de ação coletiva e sociabilidade na esfera pública?

Na perspectiva das Ciências Sociais, a discussão do atual padrão de desigualdades da sociedade brasileira passa pela compreensão de sua formação histórica. O que somos hoje, enquanto sociedade, sujeitos e atores, só pode ser entendido à luz de processos históricos que produziram certos padrões sociais, políticos e culturais. Parto de uma discussão, fundamentada em alguns autores contemporâneos, sobre a formação do Brasil e sua incorporação ao projeto de sociedade moderna. A característica central da modernidade, não seria demais repetir, é a institucionalização do universalismo - e seu duplo, a igualdade - como princípio organizador da esfera pública. Com base nesse pressuposto, argumento que em nossa sociedade, na esfera pública, duas formas de particularismo - o das diferenças e o das relações pessoais - se reforçam e articulam em diversas arenas e situações, na produção e reprodução de desigualdades sociais e simbólicas. O particularismo das diferenças produz exclusão social e simbólica, dificultando os sentimentos de pertencimento e interdependência social, necessários para a efetiva institucionalização do universalismo na esfera pública. O particularismo das relações pessoais atravessa os novos arranjos institucionais que vêm sendo propostos como mecanismos de construção de novas formas de sociabilidade e ação coletiva na esfera pública. Finalmente, considero que embora a formação de novos sujeitos sociais e políticos e de arenas de participação da sociedade na formulação e gestão das políticas públicas tragam as marcas de nossa trajetória histórica, constituem ao mesmo tempo possibilidades abertas para outra equação entre universalismo e particularismo na sociedade brasileira.

\section{A formação histórica brasileira e o debate contemporâneo}

Os determinantes históricos de nosso padrão de desenvolvimento, bem como suas implicações para as relações estado/sociedade têm sido objeto de extensa discussão entre pensadores clássicos e contemporâneos. As características "híbrida" (Freyre, 1992; Santos, 1993), "relacional" (Da Matta, 1979, 1990), as várias "gramáticas” (Nunes, 1997), resultantes de nossa trajetória histórica, se expressariam nos dilemas entre tradicional/moderno, universalismo/particularismo, individualismo/hierarquia.

Ainda que comportando diferentes ângulos de interpretação e pressupostos analíticos, com distintas implicações teóricas e políticas, há uma certa convergência na identificação de alguns elementos fundadores do edifício social e institucional brasileiro: nosso tipo de colonização, produzindo, por um lado, uma ordem estatal burocratizada, derivada do patrimonialismo ibérico e, por outro, uma organização social estruturada pela lógica particularista, "familística", dos grupos e facções. Ao mesmo tempo em que já éramos parte de um mundo póstradicional desenvolvendo suas instituições modernas e, nesse processo, tenhamos importado instituições européias - inicialmente portuguesas, mas em seguida também francesas e inglesas. A Íbero-América, imagem invertida da outra América, como a pensou Morse (1988), construída com base na escravidão, criaria, nos trópicos, suas próprias formas e conteúdos sociais, políticos e culturais.

Nosso mix institucional sui generis, que não se enquadraria nos modelos típicos e clássicos das sociedades ocidentais modernas, orientaria não só o modo brasileiro de agir na vida cotidiana, nas instituições e relações sociais, mas também as relações entre estado e sociedade. Teria igualmente produzido uma enorme capacidade da sociedade em misturar ou fazer conviver elementos de diferentes mundos institucionais, práticos e simbólicos.

Werneck Vianna (1999) identifica na interpretação de matriz weberiana sobre o Brasil, dois grandes pólos que orientarão as análises sobre os impasses enfrentados pelo país para entrar no rol das sociedades modernas. Por um lado, as leituras que associam o atraso brasileiro ao patrimonialismo derivado do transplante do Estado português para o solo nacional, como em Faoro (1987) ou Schwartzman (1988). Em outra direção, aqueles que identificam o patrimonialismo na instituição da própria organização da sociedade, como Fernandes (1975), Franco (1969) e Carvalho (1980). 
A versão que considera o patrimonialismo de herança ibérica um fenômeno do estado, conforme Werneck Vianna (1999), supõe que o capitalismo brasileiro se modernizou sem romper previamente com o passado patrimonial, o que implicaria radical autonomia do Estado frente à sociedade civil. Essa interpretação ocultaria que o atraso está nas relações patrimoniais que instituem o tecido da sociabilidade. A sociedade não compareceria como dimensão analítica, o que pressuporia que a reforma da política conteria o germe da possibilidade da boa sociedade. Para superar o atraso seria preciso estabelecer a ordem dos interesses, da competição, do mercado, da liberdade. Nesse sentido, a reforma do Estado se aplicaria no âmbito da institucionalidade política, estar dirigida à abertura do Estado à sociedade civil e aos interesses privados.

Werneck Vianna (1999) mostra que atraso e moderno sempre foram constitutivos da ambigüidade da formação brasileira. A independência em relação a Portugal não significou propriamente ruptura, mas o estabelecimento de um compromisso entre a ordem racional-legal e a patrimonial, pelo qual a burguesia passou a ter a possibilidade de extrair vantagem tanto do moderno quanto do atraso: de um lado, a economia capitalista baseada no trabalho livre; de outro, no plano da política, a preservação do estilo senhorial. A ordem competitiva não teria produzido os agentes sociais cuja vocação seria racionalizar seu mundo. Para ele, a compreensão do modo de articulação entre público e privado deveria levar em conta a trama da sociabilidade, em que a dimensão dos interesses não se tornou o lugar da inovação e resistência ao patrimonialismo, mas da conservação e do status quo.

Se a leitura sociológica procura na instituição da ordem jurídica e social os fundamentos das relações sociais contemporâneas, os significados produzidos por este processo no plano da cultura será objeto da antropologia. A importância desta separação "disciplinar" reside em que ela empresta uma outra chave conceitual para se entender o mapa desenhado pelas instituições - aqui tomadas tanto como normas quanto padrões de comportamento - que, nas diferentes esferas e arenas da vida cotidiana, orientarão formas específicas de perceber o mundo e agir sobre ele.

Da Matta (1990) mostra que diferente das formações históricas tipicamente individualistas - cujos paradigmas são as sociedades anglosaxãs -, a unidade básica, no Brasil, não estaria fundada nos indivíduos-cidadãos, mas em relações, famílias, grupos de parentes e amigos.
Em virtude disso, enquanto nos Estados Unidos o indivíduo isolado é o elemento central do sistema e, por isso, visto como algo "positivo", no Brasil, o indivíduo isolado é negativo, pois a "relação" é o elemento central do sistema. Não que em outros contextos culturais - como o norte-americano, por exemplo - isso não ocorra; essas práticas, porém, são institucionalizadas no Brasil. Compõem instrumentos conscientes e positivamente valorizados de estratégia social, pois aí convivem éticas diferenciadas, existindo códigos específicos para cada esfera de atuação.

No plano da cultura, portanto, na visão de Da Matta (1996), o "dilema sociológico brasileiro” produzido pela relação entre individualismo-universalismo/hierarquia-particularismo, e traduzindo-se também pelo par casa/rua, reproduziria o mesmo conflito básico: o da relação entre uma ordem social baseada em um sistema de relações pessoais e um conjunto de idéias liberais inventadas na Europa e Estados Unidos, e mais tarde importadas para o contexto nacional, mas correspondendo a experiências históricas radicalmente diferentes da nossa. Seríamos presas constantes da luta entre o nível formal, legal, de um sistema universalista e um conjunto de códigos pessoais de conduta não escritos, julgado natural pelas pessoas, como parte de uma lógica particularista. O liberalismo burguês, ao chegar a uma sociedade de escravos e senhores como o Brasil, transformou-se numa "ideologia que queria mercado para os inimigos e trabalhadores e proteção clientelística e subsídios governamentais para os amigos" (Da Matta, 1996:4). Introduzido num sistema escravocrata, todo o aparato legal e institucional do liberalismo teria então estabelecido uma radical liberdade para as elites, sem contudo qualquer contrapartida de igualdade em relação ao resto da população.

O dilema entre igualdade/universalismo versus hierarquia/particularismo seria estruturante de nossas cultura e instituições, perpassando práticas e expressando-se nas representações sociais. Formaria, igualmente, um dos substratos de nossa cultura política, permitindo explicar muitos dos padrões de relações entre Estado e sociedade em diferentes níveis. Explicaria, por exemplo, porque, no acesso às instituições públicas que deveria ser universal - o indivíduo "sem relações" ou “indicações" constitui-se como cidadão de segunda categoria. A construção de nossa sociedade não se fundar no indivíduo, mas nas relações pessoais, explicaria também certos comportamentos do nosso cotidiano, como o "favor", o "jeitinho", a "carteirada”, usados tanto para se conseguir acesso 
a direitos que na letra da lei são universais, quanto para ultrapassar barreiras legais, resvalando para a desonestidade e a corrupção na política.

Souza (1999) critica a visão de que o particularismo e personalismo na esfera pública, derivados de uma trajetória patrimonialista e ibérica e formando as relações no espaço público, constituiriam a principal causa de nossas mazelas. Ele prefere vincular as raízes de nosso atual padrão de desigualdades ao próprio desenvolvimento das instituições modernas no país. Em primeiro lugar, discorda de Da Matta de que a oposição casa/rua seria uma característica típica brasileira, pois a divisão público/privado estaria presente em todas as sociedades modernas. Tampouco considera idiossincrasia nossa a visão da política como um jogo desonesto, a troca de favores, a "carteirada", identificando esses elementos, por exemplo também, em um país como a Alemanha. A pouca legitimidade da política seria algo próprio do mundo contemporâneo e não apenas exclusivo do Terceiro Mundo. Nesse sentido, a corrupção, como um fenômeno estrutural à política, não teria muita relação com o personalismo e o tradicionalismo.

Souza (2001) identifica nos primórdios de nossa modernização, cujo marco foi a chegada de D. João VI, que trouxe consigo o Estado e o mercado - as duas instituições mais importantes da sociedade moderna - as bases de nossas desigualdades e do modo como se construíram nossas instituições modernas, como a cidadania. Sua tese é que, no Brasil, o Estado e o mercado jamais foram capazes de integrar efetivamente os escravos e seus descendentes. A decadência da economia e da sociedade escravocrata teria expulsado toda uma legião de inadaptados para as margens do novo sistema vencedor. Ou seja, as fontes da exclusão social brasileira teriam raízes em sua própria forma de construir a modernidade.

Quando a sociedade brasileira começa a assentar as bases de seu processo de modernização, fora das elites, ainda no século XIX, o padrão de ascensão social ou de cidadania se daria individualmente para aqueles que se identificavam com os valores do dominador, que então eram os valores impessoais do individualismo europeu. O padrão segmentado continuou pelo século XX, no qual, na década de 30 , os setores que conseguiram cidadania regulada foram os que se integraram e identificaram com o projeto modernizador estatal, quando a sociedade se impessoalizou, mas a exclusão se manteve. Para ele, em lugar de cidadania, que implica universalismo, teríamos sub e super cidadania no Brasil. No entanto, a subcidadania não seria um subproduto do não-acesso a relações personalistas privilegiadas, mas sim da forma como se deu nosso processo de modernização, nossa lógica institucional, que estaria inscrita no âmago de nosso senso comum.

Sua análise remete à dimensão subjetiva da modernidade, em que a cidadania se constrói como parte da própria formação do sujeito moderno. Uma das bases de sua discussão é Norbert Elias, que reconstitui o longo processo de formação do cidadão nas sociedades européias em que a regulação externa dos aparelhos de Estado foi sendo gradativamente substituída pela regulação interna, pela internalização das normas. Do ponto de vista do sujeito, a construção do cidadão moderno teria implicado não apenas o acesso universal aos mesmos direitos, mas a formação de uma mesma economia emocional.

Elias considerava uma certa uniformidade como o pressuposto estrutural do cidadão moderno. A equalização interna afetiva do cidadão, tanto em sua organização racional quanto em relação aos valores teria sido propiciada pelo reconhecimento da interdependência entre as diversas classes que trabalham. Por sua vez, isso só teria sido possível com o surgimento da burguesia - a primeira classe dominante da história a trabalhar. Para Souza (1999), essa consciência da interdependência social encontraria obstáculos em sociedades tão influenciadas pelo escravismo como a brasileira.

Esta análise toca em uma questão fundamental levantada pelos clássicos da sociologia, mais especificamente, por Durkheim - a sociedade como ordem moral, cujos fundamentos estão em algum tipo de solidariedade social. Pode contribuir para se entender a relação não apenas entre sociedade, Estado e valores, mas também entre essas dimensões e a qualidade e a "eficácia" das instituições - tanto na produção de pobreza e desigualdade, quanto em suas formas de enfrentá-las por meio das políticas públicas.

Procurando identificar certas condições para a ação coletiva diante do padrão de desigualdade na sociedade brasileira, Elisa Reis (1998, 2000) argumenta que a formação de um sentimento de pertencimento é crucial para a possibilidade de uma ação coletiva que permita ultrapassar as fronteiras do particularismo em direção ao universalismo. Para ela, as agudas disparidades nas condições de vida produzem diferenças tão grandes nas orientações cognitivas, que sentimentos de pertencimento simplesmente não podem se fixar. Os muito destituídos só querem proteção e, ao não se senti- 
rem pertencendo à sociedade, não podem ver a coisa pública como sua. Nesse sentido, sua participação se dá muito mais para conseguir favores do que direitos. Por outro lado, as elites não se vêem como responsáveis pelo processo e não possuem uma noção de responsabilidade social; não se vêem como parte de um todo, integrando uma coletividade. Atribuem ao Estado a responsabilidade pela não implementação correta das políticas sociais, não percebendo o Estado como parte da sociedade. Elas não vêem o problema da pobreza como algo que afete a sociedade em seu conjunto. Diferentes das elites européias que prepararam o terreno para o Estado de Bem-estar Social, nossas elites não incluiriam a erradicação da pobreza e a redução das desigualdades entre os seus interesses de fato. As desigualdades extremas fomentariam a falta de solidariedade social e a inclusão, necessárias como garantia da própria ordem social. A capacidade de empatia decresceria na medida da maior diferenciação social em relação ao outro. Esta baixa capacidade de empatia entre setores muito díspares da sociedade ameaçaria a própria cooperação social.

Consciência de interdependência social, como coloca Jessé de Souza (2001) e sentimentos de pertencimento, nas palavras de Elisa Reis (1998), são categorias que se referem, ambas, às condições de construção do sujeito/cidadão nas sociedades modernas em que a cidadania é conquistada e exercida na esfera pública, universalista e igualitária dos direitos. Na sociedade brasileira, esta questão não pode ser vista fora do quadro histórico e simbólico que produziu formas específicas de relações entre universalismo e particularismo.

\section{Universalismo e duas formas de particularismo na sociedade brasileira}

A construção do cidadão moderno implicou um tipo de orientação cognitiva, valorativa e afetiva, um substrato simbólico, permitindo estabelecer uma base comum de igualdade entre as pessoas, de forma a que estas passassem a se reconhecer como parte de uma mesma sociedade. Por base comum, refiro-me ao princípio moral crucial para que o conceito de igualdade pudesse ter-se consubstanciado socialmente - dignidade humana. Este princípio, que representa um dos fundamentos da noção moderna de indivíduo, pode ser remetido, no pensamento ocidental, à tradição judaico-cristã, com a afirmação do valor supremo e intrínseco de cada ser humano, sob a vontade soberana de Deus. Mencionado pelo profeta Eze- quiel, é desenvolvido com o cristianismo. Fortalece-se sobretudo com a Reforma e o lugar do indivíduo na doutrina protestante, pois na versão medieval havia sido, de certa maneira, subsumida pela concepção orgânica de sociedade (Johnson, 1995; Lukes, 1983). O Iluminismo reafirmou, em uma versão laica, a centralidade deste princípio e a Revolução Francesa consagrou-o, enquanto base para a noção de igualdade entre os cidadãos na esfera pública, a esfera do universal.

Como mostrou Marshall (1967) em sua obra clássica, os direitos universais e igualitários da cidadania formam a base de igualdade sobre a qual a estrutura de desigualdades econômicas, entre as classes sociais, nas sociedades modernas, foi construída. Ou seja, em uma sociedade moderna, em que direitos e mercado são instituições básicas, é preciso um patamar mínimo de igualdade, a fim de que se possa dar a competição entre os indivíduos. Mas de onde surge, como é construído esse patamar mínimo de igualdade? Com base no estoque social e simbólico que, produzido nesta sociedade, permite igualar as pessoas em termos de dignidade humana e social, a saber, torná-los propriamente indivíduos. E esse estoque social e simbólico é produzido por relações sociais historicamente construídas.

Se é certo que todas as sociedades modernas efetivamente têm uma separação entre público e privado, cada sociedade constrói essas esferas à sua própria maneira. Existe um modo específico de incorporação dos diferentes segmentos e categorias sociais ao Estado e ao mercado, e também do modo como as relações dentro de cada esfera se articulam. No Brasil, os princípios igualitários e universalistas que nas sociedades modernas regem a esfera pública, historicamente se combinaram com duas formas de particularismo: o das diferenças e o das relações pessoais. Certamente, a interseção entre universalismo e particularismo na esfera pública não constitui especificidade brasileira, mas suas configurações específicas, enquanto constitutivas do tecido social e simbólico, delimitam os contextos dentro dos quais se dão a ação coletiva e as práticas sociais de um modo geral.

Vou tomar o exemplo analisado por Heringer (2002), para discutir essas duas formas de particularismo. Ela mostra como, no Brasil, mesmo em condições iguais de escolaridade, negros e brancos possuem rendimentos diferenciados, uma situação que se agrava sobremodo nos grupos de grau de instrução mais elevado. Tal fato, segundo a autora, poderia ser atribuído à ausência, entre os negros, de redes 
pessoais que permitam acesso às melhores oportunidades de emprego; mas também poderia ser atribuído a um efeito da sub-remuneração e subutilização de mão de obra negra qualificada, decorrente da discriminação racial.

A primeira explicação enfatiza que o acesso ao mercado de trabalho, uma esfera definida pelos princípios universalistas, é otimizado pelas redes de relações de amigos, parentes, de troca de favores. Aqui não apenas entra em operação a lógica particularista, mas esta lógica se coloca como muito mais eficaz entre os grupos que já detêm posições dominantes, sejam estas econômicas, políticas, simbólicas, ou sua combinação. A segunda explicação indica que fatos produzidos historicamente são reelaborados pelas representações sociais e incorporados pelo imaginário social como "atributos naturais” de um grupo. Processos e hierarquias sociais historicamente construídas constituem "fatos sociais", os quais não existem à parte de suas representações. Na verdade - este é o ponto que eu gostaria de ressaltar-, as duas explicações não se excluem, mas se reforçam, pois indicam, em diferentes planos, como funcionam, na sociedade brasileira, algumas das relações possíveis entre universalismo e particularismo, igualdade e diferença.

\section{Diferenças}

As desigualdades sociais não se estruturam fora do jogo entre as diferenças "identitárias" e culturais, pois o simbólico é constitutivo do social. No caso brasileiro, o processo de negação de dignidade humana aos ex-escravos - e que se reproduziu para os seus descendentes, além da imensa legião de outros não-incoporados rurais e urbanos -, contribuiu para pavimentar todo um conjunto de práticas, autodefinições e representações sociais, legitimando, no plano simbólico - isto é, dos valores e das representações sociais -, o processo de exclusão das instituiçõos centrais das sociedades modernas - o Estado e o mercado.

Nesse processo de exclusão social e simbólica, em que negação de dignidade e condições de vida se reforçam mutuamente, as percepções vão sendo erguidas não apenas sobre as condições de vida dos grupos, mas sobre a condição dos membros dos grupos enquanto sujeitos e, enquanto autopercepção dos próprios sujeitos. Os atributos produzidos pelas condições de vida descolam-se destas e naturalizamse, tornando-se um estereótipo em relação ao grupo, que passa a ser associado a todos os seus membros, produzindo-se, desse jeito, uma qualidade negativa vinculada à diferença. Na me- dida em que as desigualdades das condições de vida permanecem associadas às diferenças de "pertecimento" e identidade, essas percepções se reforçam e se reproduzem na estrutura de estratificação social e simbólica.

Como a noção de igualdade tem como fundamento moral o princípio de dignidade humana, que estabelece, por intermédio de um tipo de identidade e empatia, a base para o reconhecimento da humanidade do outro, a radicalização da fragmentação social e simbólica faz com que os "diferentes" não sejam vistos e sentidos - e nessa relação, não se sintam - como portadores de dignidade. Trata-se de um processo em que os atributos relacionados às diferenças vão estabelecendo as bases dos estereótipos e preconceitos que legitimam as desigualdades em seus vários limites e gradações. O caso do índio Pataxó, incendiado em Brasília enquanto dormia por adolescentes brancos de classe média alta, é emblemático dessa negação de humanidade a um indivíduo que é ao mesmo tempo parte de um grupo "excluído" na perspectiva do mercado e dos direitos e "diferente" na perspectiva da identidade, do "pertencimento" e da interdependência como base da cooperação e da ordem social.

As percepções individuais e representações sociais, ao adquirirem condições sociais e institucionais para se reproduzirem, acabam criando vida própria, um caráter de verdade que, ao permear o imaginário social, desqualifica os membros individuais dos grupos hierarquicamente inferiores na estrutura de estratificação social e simbólica. Fundamentadas em relações históricas e sociais, a força das representações sociais está no fato de fixarem os estereótipos que delas decorrem e reafirmaremnos pela permanência das desigualdades estruturais.

Quando diferenças "identitárias” ou culturais articulam-se à pobreza, formando aquilo que vem sendo chamado de "desigualdades horizontais" (Stewart, 2002), as piores formas de exclusão se produzem. No Brasil, a combinação de indicadores de renda, educação e ocupação, com variáveis de cor e gênero, aumenta a desigualdade, como se vê, por exemplo, na relação entre anos de estudo e níveis de rendimento. Se uma mulher precisa em média estudar de 8 a 11 anos para alcançar rendimento igual ao de um homem com 1 a 3 anos de estudo, no caso das mulheres não brancas, elas devem estudar de 8 a 11 anos para alcançar o salário médio das brancas com 4 a 7 anos de estudo (Abreu et al., 1994).

Na área da saúde, em 1998, foram as mulheres brancas, com escolaridade e poder aqui- 
sitivo maiores do que as de não brancas, empregadas no setor formal da economia e pertencentes a famílias nucleares, as que mais usaram os serviços de saúde quando afastadas do trabalho por doença (Travassos et al., 2002). Dados do mesmo ano mostram que enquanto no estrato de $10 \%$ mais ricas, as brancas tiveram 3,49 consultas médicas, as negras e pardas tiveram 3,33 consultas, o que equivale a $95,4 \%$ em relação ao total de consultas das primeiras. No interior do estrato de $40 \%$ mais pobres, a desigualdade aumenta: as brancas apresentaram 2,23 consultas contra 1,94 no caso das negras e pardas, o que equivale a $87 \%$ do total de consultas das brancas (IBGE, 1998).

Os "pertencimentos" são múltiplos, e os sujeitos, ainda que se autodefinam como membros de uma comunidade maior, fazem parte de grupos que se classificam segundo critérios de diferença - cor, raça, classe, identidade cultural, religião etc. Estes não operam apenas no reforço das desigualdades econômicas, mas também daquelas produzidas em outras esferas, como educação e saúde, contribuindo para conformar um determinado padrão de desigualdades sociais. O modo como em cada sociedade, as diferenças - vale dizer, as multiplicidades de "pertencimentos" e identidades - se articulam ao funcionamento do mercado e do Estado, define uma das partes da equação entre universalismo e particularismo.

A outra parte diz respeito à ação coletiva e intervenção do Estado sobre desigualdade por meio das políticas públicas. Passo então, à segunda forma de particularismo - o das relações pessoais na esfera pública - e suas implicações para o quadro dentro do qual se dá a ação coletiva. Abordo a institucionalização de algumas arenas de participação da sociedade na formulação e gestão das políticas públicas que, especialmente a partir dos anos 90, vêm sendo propostas como novos arranjos institucionais e paradigmas de ação coletiva na esfera pública.

\section{Relações pessoais}

Na última década, como parte de uma tendência internacional e convergindo com políticas de diminuição e descentralização das funções do Estado, a participação da sociedade civil passou a ser considerada como mecanismochave na gestão de políticas descentralizadas. Particularmente após o trabalho de Putnam (1996), nos discursos sobre os países periféricos assumiu-se a sociedade civil como uma espécie de receita para se criar instituições capazes de promover o bom desempenho governamental, o desenvolvimento econômico e mino- rar as desigualdades sociais. Capital social, cultura cívica e empowerment tornaram-se as novas palavras de ordem no vocabulário das agências internacionais, organizações não governamentais, movimentos sociais e partidos dentro de um variado espectro político e ideológico.

O papel da sociedade na formulação, implementação e acompanhamento das políticas fortaleceria ao mesmo tempo as capacidades sociais, pessoais e políticas de indivíduos pertencentes a grupos de menor renda e educação; enfraqueceria as relações clientelísticas locais, estimulando uma cultura democrática e garantindo eficiência, efetividade e abrangência das políticas públicas; o que, por sua vez, criaria condições institucionais para o desenvolvimento e a melhoria das condições de vida (Banco Mundial, 1997; Faguet, 1997; Kliksberg, 1999).

No Brasil, a Constituição de 1988 fomentou a construção de arenas públicas locais; em alguns setores, a legislação instituiu a participação dos representantes de associações e organizações representativas da sociedade na gestão das políticas públicas, como no caso dos Conselhos de Saúde. Em certas situações, como na implementação do Orçamento Participativo, os próprios governos locais induziram a incorporação da sociedade, com o objetivo de democratizar os processos decisórios e garantir o controle social sobre o governo. Em outros casos, como parte de inovações no redesenho das funções estatais, notadamente nos setores sociais em comunidades de baixa renda, o Estado transferiu a organizações comunitárias e não governamentais a gestão de certos serviços públicos.

Ainda que de diferentes maneiras e com objetivos políticos e ideológicos muitas vezes divergentes, todos esses novos arranjos institucionais buscam aproximar Estado e sociedade civil para conseguir melhores resultados do desempenho dos governos. Tais formas de participação da sociedade civil e constituição de atores políticos, ao incorporarem representantes de vários segmentos da sociedade em estruturas decisórias, deliberativas ou gerenciais públicas, enfraqueceriam as relações clientelistas e promoveriam mudanças na cultura política e cívica - além de propiciar a aplicação mais eficiente dos recursos públicos. Representariam um movimento reforçando a lógica universalista em detrimento do particularismo. Vários estudos, contudo, apontam que além de esses novos arranjos institucionais freqüentemente serem re-significados por relações sociais e políticas locais particularistas, os atores governamentais podem ter um lugar central na 
mobilização da sociedade e condução universalista das políticas públicas.

Analisando a implementação do Orçamento Participativo em Niterói no final da década de 90, Bezerra (M. O. Bezerra, 2001, em apresentação feita durante o Seminário Saúde e Desigualdade: Instituições e Políticas Públicas no Século XXI) mostrou como a participação popular na gestão das políticas públicas, mesmo que estabelecendo uma oportunidade para a renovação das relações políticas e procurando difundir a concepção de que os serviços constituíam um direito que cumpria ao poder público atender, foi retraduzida no contexto dos conflitos locais, formas de sociabilidade política e interação tradicionais. Embora o deslocamento da decisão da aplicação de recursos para a população tenha tido, entre seus objetivos, a substituição das noções de "favor", "pedidos" e "ajuda” por "participação" e "direitos", permanecia, nas trocas políticas entre representantes do poder público municipal, vereadores e associações de moradores, a linguagem tradicional das relações pessoais e dos grupos.

Quanto aos Conselhos de Saúde, apesar de já estarem atualmente implantados em todos os municípios brasileiros, Labra (2002), com base em estudos de caso em oito estados da Federação, é pessimista quanto à "qualidade" da participação dos representantes da sociedade civil. Com exceção de Porto Alegre, a população geralmente ignorava a existência e os objetivos dos conselhos e as associações locais não se interessavam em nomear representantes. Era comum as autoridades boicotarem a participação e as iniciativas populares, além da cooptação das lideranças locais mediante troca de favores e benesses.

Nas parcerias entre sociedade civil e Estado na gestão de serviços públicos, a lógica das relações pessoais também está presente. Claro (2002) estudou a gestão comunitária de uma unidade de saúde em uma favela no Rio de Janeiro, efetivada por meio de contrato entre uma organização não governamental formada com este objetivo e a Secretaria Municipal de Saúde. Ele constatou que a inovação não promoveu a participação democrática da comunidade, nem evitou a interferência das relações pessoais para o acesso mais fácil aos serviços, agravado pela interferência do narcotráfico. Os moradores eram alijados dos processos decisórios e os recursos de poder criados pela gestão comunitária eram canalizados sobretudo para os membros da comunidade diretamente envolvidos no processo de gestão. Verificou também que, muitas vezes, eram os próprios representantes do Estado, isto é, os profissionais da secretaria municipal que, diante de práticas de favorecimento pessoal, procuravam fomentar, junto aos gestores comunitários, procedimentos universalistas no atendimento aos usuários.

Outras experiências também relativizam o lugar da sociedade civil na condução da boa política e mostram o papel dos atores governamentais na mobilização e organização da população, como no caso do Orçamento Participativo em Porto Alegre (Abers, 1998), e na criação de confiança e civismo entre prestadores de serviços públicos e usuários, como no "bom governo” no Ceará, analisado por Tendler (1998). Criticando o pressuposto de que o bom desempenho das políticas públicas depende da existência de uma sociedade civil bem desenvolvida, sua análise mostra justamente o contrário: a atuação do governo estadual foi decisiva inclusive para a formação e organização da sociedade civil, que passou a reivindicar melhor desempenho governamental.

Nem sempre a sociedade é o "lugar da inovação e resistência”, visto que ela não é a imagem invertida do Estado. Ambos são dimensões analíticas de um mesmo processo, uma mesma formação histórica, que produz não apenas determinada institucionalidade e formas de sociabilidade, mas certos significados culturais, mapas para ação, individual e coletiva. A participação das organizações da sociedade civil nas arenas públicas, locais e nacionais, como parte de uma relação com o Estado, se constrói como parte desses mapas - culturais, políticos e cívicos - pré-existentes, ainda que a ação dos diferentes atores, nas arenas estatais e societárias, seja justamente o que irá modificá-los.

\section{Conclusões}

Com base no debate contemporâneo sobre a formação brasileira, procurei fazer algumas reflexões sobre as perguntas colocadas inicialmente. Focalizei duas formas de particularismo que historicamente vêm estruturando e reforçando as desigualdades no Brasil: o das diferenças e o das relações pessoais. Enquanto a primeira forma filtra as posições no mercado e o exercício dos direitos, a segunda funciona como mecanismo de acesso ou barreira aos bens públicos.

O mercado é o espaço da competição entre indivíduos universais e iguais em direitos, mas o acesso ao mercado e aos direitos são constrangidos por critérios particularistas. Na competição no mercado, no exercício dos direitos e nas arenas de participação da sociedade na 
gestão das políticas públicas, entram em jogo as características de pertencimento atribuídas a determinados grupos e/ou a lógica das relações pessoais.

Quanto mais o particularismo das diferenças reforça as desigualdades horizontais, mais difícil se torna a formação da consciência de interdependência social e pertencimento em relação ao estoque social e simbólico da sociedade e menos efetiva é a institucionalização do universalismo na esfera pública. Quanto mais as práticas e significados particularistas se inscrevem nas arenas públicas e nas relações entre sociedade e Estado, menos eficazes tornam-se as instituições.

Do ponto de vista da ação coletiva, o combate às desigualdades e o exercício efetivo dos direitos, por parte de todos os segmentos e grupos sociais, passa por vários desafios. Um deles seria a construção de um estoque social e simbólico comum, possibilitando incorporar, sem hierarquizar, as diferentes experiências que dão sentido de pertencimento a grupos específicos. A produção de valores fomentando este sentimento teria também, de certo modo, que passar por algum tipo de re-significação de nosso hibridismo institucional e cultural, retendo, da tradição brasileira, sobretudo sua capacidade de tolerância e inovação.

O outro desafio seria o fortalecimento de instituições permitindo eliminar as barreiras que as distintas formas de particularismo estabelecem para o acesso ao mercado e aos direitos. A constituição de novos atores e arranjos institucionais não poderia deixar de trazer consigo as práticas e os significados produzidos por uma certa trajetória histórica. Formas e conteúdos sociais, políticos e culturais não se reproduzem independentemente de suas condições de produção, mas os processos sociais, ao implicarem sempre, e ao mesmo tempo, permanência e mudança, se apresentam como um desenho aberto e imprevisível quanto aos seus resultados. Se o particularismo das relações pessoais não desaparece da esfera pública, quando novas formas institucionais de participação da sociedade civil entram em operação, no entanto, estas novas formas, seguramente, estão abrindo o caminho para uma outra equação entre universalismo e particularismo na sociedade brasileira.

\section{Referências}

ABERS, R., 1998. From clientelism to cooperation: Local government, participatory policy, and civic organizing in Porto Alegre, Brazil. Politics \& Society, 26:511-537.

ABREU, A. P.; JORGE, A. \& SORJ, B., 1994. Informalidade e Precariedade: Gênero e Raça no Brasil em 1990. Série Seminários 7/94. Rio de Janeiro: Instituto de Pesquisa Econômica Aplicada.

BANCO MUNDIAL, 1997. O Estado num Mundo em Transformação - Relatório sobre o Desenvolvimento Mundial. Washington, DC: Banco Mundial.

CARVALHO, J. M., 1980. A Construção da Ordem. Rio de Janeiro: Campus.

CLARO, I. B., 2002. Gestão Comunitária: Estudo de uma Nova Articulação Estado/Sociedade Civil no Parque Proletário de Vigário Geral. Dissertação de Mestrado, Rio de Janeiro: Escola Nacional de Saúde Pública, Fundação Oswaldo Cruz. 
DA MATTA, R., 1979. Carnavais, Malandros e Heróis Para uma Sociologia do Dilema Brasileiro. Rio de Janeiro: Zahar Editores.

DA MATTA, R., 1990. For an Anthropology of the Brazilian Tradition. Working Paper 182. Washington, DC: Latin American Program, The Wilson Center.

DA MATTA, R., 1996. Globalização e Identidade Nacional: Considerações a partir da Experiência Brasileira. Rio de Janeiro: Organização das Nações Unidas para a Educação, Ciência e Cultura/Conjunto Universitário Cândido Mendes. (mimeo.)

FAGUET, J. P., 1997. Descentralization and Local Government Peformance. Technical Consultation on Decentralization, Food and Agriculture Organization. 27 October $2000<w w w . f a o . o r g / S D /$ Rodirect/ Rofo0032.htm>.

FAORO, R., 1987. Os Donos do Poder. Rio de Janeiro: Editora Globo.

FERNANDES, F., 1975. A Revolução Burguesa no Brasil. Rio de Janeiro: Zahar.

FRANCO, M. S. C., 1969. Homens Livres na Ordem Escravocrata. São Paulo: Instituto de Estudos Brasileiros, Universidade de São Paulo.

FREYRE, G., 1992. Casa Grande \& Senzala. Rio de Janeiro: Record.

HERINGER, R., 2002. Desigualdades raciais no Brasil: Síntese de indicadores e desafios no campo das políticas públicas. Cadernos de Saúde Pública, 18 (Sup.):57-65.

IBGE (Fundação Instituto Brasileiro de Geografia e Estatística), 1998. Pesquisa Nacional de Amostra por Domicílio - PNAD. Rio de Janeiro: IBGE.

JOHNSON, P., 1995. História dos Judeus. Rio de Janeiro: Imago Editora.

KLIKSBERG, B., 1999. Capital social y cultura, claves esenciales del desarrollo. Revista de la CEPAL, 69:85-102.

LABRA, M. E., 2002. Processo Decisório e Conselhos de Saúde. Balanço a Partir da Produção Acadêmica (1996-2001). Relatório de Pesquisa. Rio de Janeiro: Escola Nacional de Saúde Pública, Fundação Oswaldo Cruz.

LUKES, S., 1983. Individualism. London: Basil Blackwell.

MARSHALL, T. H., 1967. Cidadania, Classe Social e Status. Rio de Janeiro: Zahar.
NUNES, E. O., 1987. A Gramática Política Brasileira. Rio de Janeiro: Zahar Editores/Escola Nacional de Administração Pública.

PUTNAM, R. D., 1996. Comunidade e Democracia - A Experiência da Itália Moderna. Rio de Janeiro: Editora FGV.

REIS, E. P., 1998. Processos e Escolhas - Estudos de Sociologia Política. Rio de Janeiro: Contracapa.

REIS, E. P., 2000. Percepções da elite sobre pobreza e desigualdade. Revista Brasileira de Ciências Sociais, 15:143-152.

SANTOS, W. G., 1993. As Razões da Desordem. Rio de Janeiro: Rocco.

SCHWARTZMAN, S., 1988. Bases do Autoritarismo Brasileiro. Rio de Janeiro: Campus.

SOUZA, J., 1999. O Malandro e o Protestante - A Tese Weberiana e a Singularidade Cultural Brasileira. Brasília: Editora UnB.

SOUZA, J., 2001. A sociologia dual de Roberto Da Matta: Descobrindo nossos mistérios ou sistematizando nossos auto-enganos? Revista Brasileira de Ciências Sociais, 16:47-67.

STEWART, F., 2002. Horizontal Inequalities: A Neglected Dimension of Development. WIDER Annual Lectures 5. Helsinki: World Institute for Development Economics Research, United Nations University.

TENDLER, J., 1998. Bom Governo nos Trópicos - Uma Visão Crítica. Brasília: Escola Nacional de Administração Pública/Revan.

TRAVASSOS, C.; VIACAVA, F.; PINHEIRO, R. \& BRITO, A., 2002. Utilização dos serviços de saúde no Brasil: Gênero, características familiares e condição social. Revista Panamericana de Salud Pública, 11:365-373.

WERNECK VIANNA, L., 1999. Weber e a interpretação do Brasil. In: O Malandro e o Protestante - A Tese Weberiana e a Singularidade Cultural Brasileira (J. Souza, org.), pp. 173-193, Brasília: Editora da UnB.

Recebido em 7 de maio de 2002

Versão final reapresentada em 27 de setembro de 2002 Aprovado em 15 de outubro de 2002 